\title{
Survey on joint hypermobility in university students aged $18-25$ years old
}

\author{
Darcisio Hortelan Antonio and Claudia Saad Magalhaes
}

\begin{abstract}
Background: Joint hypermobility is defined as a wide range of movements beyond the physiological limits, it has been recognized in healthy people, gymnasts, acrobats, and carriers of genetic affections of connective tissue. A survey among young adults was conducted to describe the frequency of joint hypermobility, estimating its impact on function and quality of life.

Methods: Volunteer university students aged 18 to 25 years old who answered a valid 5-item questionnaire about hypermobility, a physical activity questionnaire, and the Brazilian version of the Medical Outcome Survey Short Form 36 (SF-36) were included. Hypermobility was also assessed by a guided self-examination, with Beighton's criteria being scored and scores greater than or equal to 4 or less than 4 being discriminated.

Results: A total of 388 subjects were included, of which 299 were women (77.06\%) and 89 were men (22.94\%); the median age was 23 years old. Generalized joint hypermobility (Beighton score $\geq 4$ ) was observed in 104 individuals (26.8\%). Localized hypermobility (Beighton score 1-3) was observed in 135 (34.79\%) individuals, where the hypermobility of the 5th finger was the most frequent in 165 (57.47\%) individuals, followed by hypermobility of the thumb in 126 (32.56\%) individuals, hypermobility of the elbows and knees each in 72 (18.6\%) individuals, and hypermobility of the spine in $69(17.79 \%)$ individuals. The descriptive observation of physical activity indicated regular practice. The correlation coefficients between the SF-36 domains and hypermobility scores were very low and statistical comparison not significant.
\end{abstract}

Conclusion: In this population of youngsters, predominantly women, localized hypermobility was more frequent than generalized hypermobility; however, with low impact on health domains and quality of life scores, estimated in each domain of the SF-36, the physical and mental component scores, and the time dedicated to physical activity.

Keywords: Joint hypermobility, Generalized hypermobility, Localized hypermobility, SF-36 health questionnaire

\section{Background}

Hypermobility is defined as the wider range of movements beyond the limits considered physiological. It has been recognized as a phenomenon frequently observed in healthy people, acrobats, gymnasts, and ballerinas [1-5]. Hypermobility is also part of the syndromic presentation of certain genetic diseases, [6] such as Ehler-Danlos Syndrome, Marfan Syndrome, Down Syndrome, Osteogenesis imperfecta, and Stickler Syndrome, among others.

\footnotetext{
* Correspondence: claudi@fmb.unesp.br

Pediatrics Department, Botucatu Medical School, Graduate Program in Public Health of UNESP, Sao Paulo State University UNESP, Avenida Prof. Mario Rubens Guimarães Montenegro SN, Campus da Unesp, Rubião Junior, CEP, Botucatu, SP 18618-687, Brazil
}

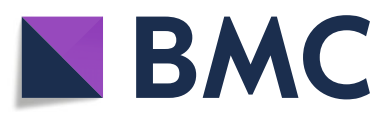

(c) The Author(s). 2018 Open Access This article is distributed under the terms of the Creative Commons Attribution 4.0 International License (http://creativecommons.org/licenses/by/4.0/), which permits unrestricted use, distribution, and

reproduction in any medium, provided you give appropriate credit to the original author(s) and the source, provide a link to the Creative Commons license, and indicate if changes were made. The Creative Commons Public Domain Dedication waiver (http://creativecommons.org/publicdomain/zero/1.0/) applies to the data made available in this article, unless otherwise stated. rheumatic condition leading to chronic musculoskeletal symptoms, emerged in the 1970s with several case series and population studies identifying the association with chronic musculoskeletal pain $[7,8]$ and, more recently, with dysautonomia and gastrointestinal dysmotility [7-9].

The incidence and prevalence of hypermobility vary greatly among populations, with marked differences according to age, gender, ethnicity, physical activity, or sports and athletic abilities. Approximately $25-50 \%$ of children younger than 10 years old have some degree of hypermobility [10-17]. There is a higher prevalence in populations of Asian origin, followed by populations of African and European origins $[10,12,14,15,17-26]$. However, 
comparisons among different populations have been hampered by the use of different criteria and methodologies for the evaluation of hypermobility.

Most clinicians recognize joint hypermobility in routine practice and by the use of the range of motion scale assessment proposed by Beighton [20]. The presence or absence of hypermobility in the joints is categorized, signaling the flexibility of five areas of the body with extension beyond the physiological limits. The maneuvers that make up the Beighton scale represented in Fig. 1 are 1) extension of 5th metacarpal phalangeal joint by placing the 5th finger parallel to the forearm, 2) extension of the thumb touching the flexor side of the forearm, 3) extension greater than $10^{\circ}$ beyond the limit of $180^{\circ}$ of the elbow, 4) extension greater than $10^{\circ}$ beyond the limit of $180^{\circ}$ in the knee, and 5) flexion and elongation of the spine by placing the hands flat on the floor with the knees in maximum extension. These maneuvers are individually scored on each side of the body and spine, to a total of 9 points. Scores greater than or equal to 4 are classified as generalized joint hypermobility, and scores 1-3 are classified as localized joint hypermobility $[1,4,27]$.

Physiotherapists are trained to identify reduced range of motion and its clinical repercussions, associating it with several conditions of inflammatory origin. Greater ranges of movement are interpreted as variations of the normality of individual characteristics. Intervention with physical exercises still does not result in consistent evidence because a systematic review of intervention with exercises for those with functional repercussions was not conclusive regarding the effectiveness of the intervention with exercises or physical activity on hypermobility and its functional repercussions [28].

A wide spectrum of extra-articular clinical manifestations has been progressively recognized in association with musculoskeletal symptoms [29], such as predisposition to ecchymosis, poor wound healing, early onset of osteoarthritis, valvulopathy, osteoporosis, vesicoureteral reflux, inguinal hernia, and changes in intestinal motility $[5,6,26,30-33]$. There are also other manifestations, such as fatigue, anxiety, and depression, negatively affecting social function and well-being [34].

The main musculoskeletal manifestation is chronic and generalized pain $[7,9,17,26,35]$. Proprioceptive functions may also be adversely affected, possibly due to damage to mechanical connective tissue receptors. Failure to recognize extreme joint range of movement can lead to joint instability and traumas to repetitive stress [36-38]. Decreased muscle strength can occur in children with limb pain and joint hypermobility [39]. There is evidence that hypermobility syndrome is a multisystemic manifestation, incorporating three main components: chronic pain, autonomic dysfunction, and dysfunction of gastrointestinal motility $[6,8,26,30,32,39,40]$.
There have been few population studies on the impact of hypermobility among young adults. The frequencies of generalized and localized hypermobility have been widely studied in several populations, including the Brazilian pediatric population of pre-schoolers and schoolchildren $[10,14,21]$; however, studies on adolescents and young adults are scarce in the global literature $[11,16]$ and have not been referred to our population.

\section{Objective}

To investigate the frequency of joint hypermobility among university students 18 to 25 years old through survey and self-examination, estimating its functional impact and its impact on quality of life through the Medical Outcome Survey Short Form 36 (SF-36) questionnaire.

\section{Methods}

Volunteers between 18 and 25 years of age from medical and physiotherapy courses were invited to participate in this study after the work team provided explanations about the study.

The project obtained institutional ethics committee approval (CEP-457/2010) and agreement from the course councils; the subjects who agreed were included in the study by signing the Terms of Free and Informed Consent. The research was conducted in accordance with the Helsinki Declaration for research on humans beings.

Participants completed the self-administered questionnaires on hypermobility, including a valid five-item questionnaire adapted by Moraes et al. [41] and a survey on multisystemic associations of hypermobility syndrome [26]. The Brazilian version of the SF-36 [42] was completed by the subjects, and their records were identified by alpha-numerical code without personal identification. The self-examination was observed and recorded in case report forms by three trained observers, and the data were transferred to analysis worksheets.

The SF-36 is a widely used measure of health-related quality of life. The purpose of this questionnaire is to detect clinically and socially relevant differences in the health conditions of both the general population and individuals affected by certain diseases, along with any changes in health status over time through a small number of statistically efficient dimensions. The SF-36 consists of 36 items in 8 domains: Physical Functioning (CF) , Role-Physical (RF), Bodily Pain (BP), General Health (GH), Vitality (VT), Social Functioning (SF), RoleEmotional (RE), and Mental health (MH), resulting in two summary components, the Physical Component (PCo) and the Mental Component (MCo). The score ranges from 0 to 100 points, where 0 represents the 
worst state of health and 100 the best state of health in the last 4 weeks.

A single evaluation was performed; there was no gender selection, and participation was voluntary, with consecutive inclusion of participants until reaching the sample size estimated by means of statistical calculation. The specific musculoskeletal examination, which includes hypermobility maneuvers, was instructed and conducted according to the scheme outlined in Fig. 1.

The sample size was calculated considering the prevalence of hypermobility in this specific age group as unknown $(p=0.50)$, with a reliability of $95 \%$ and a margin of error of $5 \%$. The minimum size calculated for the sample was 385 subjects, and the maximum was 400 subjects.

The descriptive analysis of the frequency of signs and symptoms of the joint hypermobility survey and of the Beighton scale score was performed. Qualitative variables were described by absolute and percentage frequencies. Quantitative variables were described by medians and variation ranges (minimum-maximum) or means and standard deviations when appropriate. SF-36 scores on valid questionnaires $(<5 \%$ lost data) were calculated using SAS for Windows software version 9.3.

The frequency of hypermobility was scored individually by determining the frequency of joints scored and compared by gender. The comparison of hypermobility areas in men and women was performed using Student's $t$ test (two categories). The categorization of generalized hypermobility by means of the limit of 4 or more joints scored using the Beighton criteria was also estimated according to the frequencies and possible associations explored.
The association tests between the hypermobility parameters and the SF-36 domain scores with the respective summary scores were performed using the Pearson Correlation Test. The association is represented by the Pearson $\mathrm{r}$, and the significance is expressed by the values of $p<0.05$. Correlations $<0.4$ were considered weak or with no association, those between 0.4 and 0.7 were considered moderate, and those $>0.7$ were considered strong.

\section{Results}

The participants of the research were volunteers who agreed to participate in the study through signing the Terms of Informed Consent. There was no refusal to participate. The sample consisted of 388 subjects, of which 28 were from the Medicine course and 360 were from the Physiotherapy course. The evaluation period was from February 2013 to April 2014.

A total of 388 subjects were recruited, including 299 women (77\%) and 89 men (23\%), with a minimum age of 18 years and a maximum age of 25 years (median 23 ), with the following anthropometric characteristics: mean weight $(64.5 \pm 15.7)$, median weight $60 \mathrm{~kg}$, mean height $(1.66 \pm 0$. $09)$, and median height $1.65 \mathrm{~m}$. The mean body mass index (BMI) was $(23 \pm 4)$, and the median BMI was 22 .

The self-evaluation of physical activity, by means of estimating the number of hours per week of practice of leisure activities, sports, and competitions, was compiled. The descriptive analysis was as follows: 165 declared a mean leisure activity practice time of $(1.7 \pm 2.9)$ hours/week; 124 subjects declared a mean sports practice time of $(1.6 \pm 3.2)$

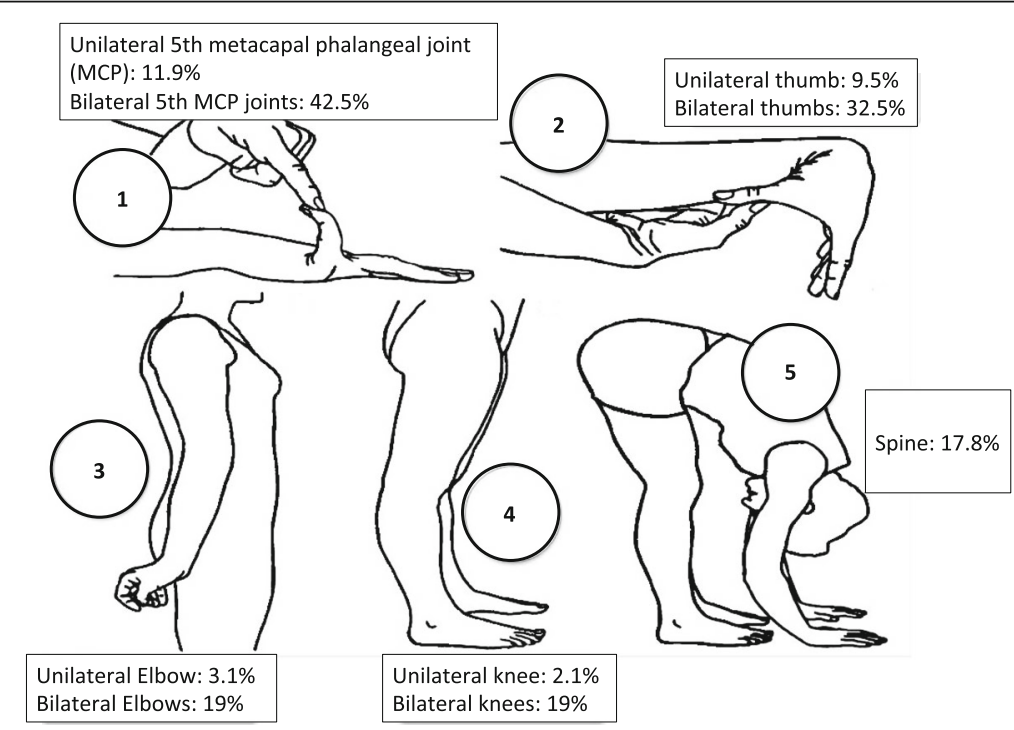

Fig. 1 Percentage frequencies of unilateral or bilateral signs of hypermobility identified through 5 maneuvers in the Beighton scale: 1) extension of the 5th metacarpal phalangeal joint by placing the 5th finger parallel to the forearm, 2) extension of the thumb touching the flexor side of the forearm, 3) extension greater than $10^{\circ}$ beyond the limit of $180^{\circ}$ of the elbow, 4) extension greater than $10^{\circ}$ beyond the limit of $180^{\circ}$ in the knee, and 5) flexion and elongation of the spine by placing the hands flat on the floor with knees in maximum extension 
Table 1 Frequencies of responses on hypermobility, described in a 5-item questionnaire for joint hypermobility [41]

\begin{tabular}{|c|c|c|c|}
\hline & Yes & No & Do not know \\
\hline $\begin{array}{l}\text { 1. Can you or have you managed to get your hands placed flat on the floor } \\
\text { without bending your knees? }\end{array}$ & $187(48.2 \%)$ & $188(48.4 \%)$ & $13(3.4 \%)$ \\
\hline 2. Can you or have you been able to turn your thumb until it touches your forearm? & $101(26 \%)$ & $278(71.7 \%)$ & $9(2.3 \%)$ \\
\hline $\begin{array}{l}\text { 3. When you were a kid, did you amuse your friends by twisting your body in strange } \\
\text { positions OR did you open your legs completely? }\end{array}$ & $153(39.4 \%)$ & $229(59 \%)$ & $6(1.6 \%)$ \\
\hline 4. As a child or teenager have you dislocated your shoulder or patella more than once? & $29(7.5 \%)$ & $348(89.7 \%)$ & $11(2.8 \%)$ \\
\hline $\begin{array}{l}\text { 5. Do you consider your joints supple? Do you think your joints bend as much as those } \\
\text { of a contortionist? }\end{array}$ & $31(8 \%)$ & $337(86.9 \%)$ & $20(5.1 \%)$ \\
\hline
\end{tabular}

hours/week, and 23 subjects declared a mean competition practice time of $(0.2 \pm 1.2)$ hours/week.

The responses to the 5-item hypermobility questionnaire, estimating the presence or absence of joint hypermobility, are presented in Table 1. Among the most scored items, the highest was the spine (48.2\%).

The survey on musculoskeletal and extra-articular or systemic complaints associated with joint hypermobility and their respective frequencies is presented in Table 2. The most frequently reported problem was low back pain, present in 176 (45.4\%) of the subjects.

The classification of hypermobility was established using the instructed self-examination recorded by three trained observers, using the criteria of Beighton [20], with a limit of 4 or more joints $(\geq 4)$ to determine generalized hypermobility and a 3 -joint limit $(\geq 1$ and $\leq 3$ ) for localized hypermobility [43].

Generalized joint hypermobility was observed in 104 (26.8\%) individuals. The frequency of generalized joint hypermobility in women was $27.8 \%$, and that of the male

Table 2 Frequencies of valid responses in the inquiry of signs and symptoms, musculoskeletal and systemic, related to joint hypermobility

\begin{tabular}{lll}
\hline Signs and symptoms & Yes & No \\
\hline Contortionist tricks & $54(15 \%)$ & $328(85 \%)$ \\
Ankle sprain & $118(32 \%)$ & $255(68 \%)$ \\
Other ligament injuries & $55(15 \%)$ & $309(85 \%)$ \\
Arthralgia & $122(33 \%)$ & $252(67 \%)$ \\
Arthritis & $18(5 \%)$ & $356(95 \%)$ \\
Frequent cramps & $143(37 \%)$ & $243(63 \%)$ \\
Pain in the knees & $102(27 \%)$ & $278(73 \%)$ \\
Cervical pain & $107(28 \%)$ & $270(72 \%)$ \\
Dorsal pains & $111(29 \%)$ & $268(71 \%)$ \\
Lower back pain & $176(46 \%)$ & $206(54 \%)$ \\
Shoulder dislocations & $29(8 \%)$ & $355(92 \%)$ \\
Patella dislocations & $16(4 \%)$ & $362(96 \%)$ \\
Poor wound healing & $28(7 \%)$ & $351(93 \%)$ \\
Fractures & $79(20 \%)$ & $304(80 \%)$ \\
\hline
\end{tabular}

population was $23.6 \%$. The locations of the hypermobility signs and their respective frequencies and distributions are shown in Fig. 1, with the paired signs being independently and bilaterally scored in the majority.

The 5th finger hypermobility sign was the most frequent, being described in 165 (42.52\%) individuals, followed by the thumb in 126 (32.56\%) individuals, elbows and knees in 72 subjects each (18.6\%), and spine in 69 (17. $79 \%)$ individuals. There were no statistically significant differences in gender for any of the signs (Table 3).

In the SF-36 questionnaire, the results were comparable with the normative data in adults of the Brazilian population. No significant differences were observed in the results of each domain and in the physical and mental indices among those with generalized hypermobility, localized hypermobility, or absence of hypermobility (Table 4).

The following correlations were found between each SF-36 domain and the generalized hypermobility condition (score $\geq 4$ ): Vitality (VT) $r=-0.05284, p=0.2991$; Mental Health $(\mathrm{MH}) r=-0.10007, p=0.05$; Physical Functioning (PF) $r=-0.04907, p=0.3350$; Role-Physical (RP) $r=-0.03178, p=0.5325$; Bodily Pain $r=0.07304$, $p=0.1510$; General Health (GH) $r=-0.11050, p=0.03$; Role-Emotional (RE) $r=-0.02224, p=0.6623$; Social Functioning (SF) $r=-0.05410, p=0.2878$; Physical Component (PCo) $r=-0.06839, p=0.1789$; and Mental Component (MCo) $r=-0.02491, p=0.6248$. All correlations were weak ( 0.1 to 0.3$)$, although they were significant for Mental Health and General

Table 3 Comparison of the frequencies of joint hypermobility signs scored in the Beighton Scale according to gender (Student's t-test)

\begin{tabular}{lllll}
\hline Sign Manouver & Men & Women & Total & $p$ \\
\hline 1) 5 th Finger & $32 / 89(35.95 \%)$ & $133 / 299(44.48 \%)$ & $165(42.52 \%)$ & NS* $^{*}$ \\
2) Thumb & $24 / 89(26.96 \%)$ & $102 / 299(34.11 \%)$ & $126(32.56 \%)$ & $N^{*}$ \\
3) Elbow & $9 / 89(10.11 \%)$ & $63 / 299(21.07 \%)$ & $72(18.6 \%)$ & $N^{*}$ \\
4) Knee & $11 / 89(12.35 \%)$ & $61 / 299(20.40 \%)$ & $72(18.6 \%)$ & NS $^{*}$ \\
5) Spine & $14 / 89(15.73 \%)$ & $55 / 299(18.39 \%)$ & $69(17.79 \%)$ & NS $^{*}$ \\
\hline
\end{tabular}

*NS - not significant 
Table 4 Comparison of the SF-36 scores in the total sample of volunteers, without hypermobility (Beighton score $=0$ ) or with localized hypermobility (1-3) and generalized hypermobility $(\geq 4)$

\begin{tabular}{|c|c|c|c|c|c|c|c|c|c|}
\hline Variable & $n$ & Total Sample & Median & $N(\%)$ & $\begin{array}{l}\text { Localized hypermobility (1-3) } \\
\text { Without hypermobility (0) }\end{array}$ & Median & N (\%) & $\begin{array}{l}\text { Generalized } \\
\text { hypermobility }(\geq 4)\end{array}$ & Median \\
\hline$\overline{P F}$ & 388 & $88.2 \pm 12.4$ & 90 & $284(73.2 \%)$ & $88.3 \pm 12.7$ & 90 & $104(26.8 \%)$ & $87.7 \pm 11.5$ & 90 \\
\hline $\mathrm{RP}$ & 388 & $72.4 \pm 31$ & 75 & 284 (73.2\%) & $73.9 \pm 30$ & 75 & $104(26.8 \%)$ & $68 \pm 33.3$ & 75 \\
\hline $\mathrm{BP}$ & 388 & $51.7 \pm 8.1$ & 50 & 284 (73.2\%) & $51.3 \pm 8.5$ & 50 & $104(26.8 \%)$ & $52.6 \pm 7$ & 50 \\
\hline $\mathrm{GH}$ & 388 & $60.8 \pm 15.5$ & 65 & 284 (73.2\%) & $61.7 \pm 15.3$ & 65 & $104(26.8 \%)$ & $58.4 \pm 15.8$ & 60 \\
\hline VT & 388 & $54.8 \pm 19.7$ & 57.5 & $284(73.2 \%)$ & $55.4 \pm 19.3$ & 60 & $104(26.8 \%)$ & $53.1 \pm 20.7$ & 55 \\
\hline SF & 388 & $64 \pm 11.5$ & 65.1 & 284 (73.2\%) & $64.4 \pm 11.5$ & 65 & $104(26.8 \%)$ & $62.8 \pm 11.3$ & 64.8 \\
\hline RE & 388 & $67.2 \pm 38.2$ & 100 & $284(73.2 \%)$ & $67.5 \pm 37.7$ & 100 & $104(26.8 \%)$ & $66.4 \pm 39.6$ & 100 \\
\hline $\mathrm{MH}$ & 388 & $65 \pm 19.4$ & 68 & 284 (73.2\%) & $66 \pm 19.7$ & 68 & $104(26.8 \%)$ & $62 \pm 18.3$ & 64 \\
\hline PCo & 388 & $65.5 \pm 11$ & 67 & $284(73.2 \%)$ & $66.1 \pm 10.9$ & 67.5 & $104(26.8 \%)$ & $64 \pm 11$ & 65.5 \\
\hline MCo & 388 & $61.3 \pm 16.3$ & 64.2 & $28473.2 \%$ & $61.6 \pm 16.2$ & 64.6 & $10426.8 \%$ & $60.7 \pm 16.6$ & 61.7 \\
\hline
\end{tabular}

Physical Functioning (PF), Role-Physical (RP), Bodily Pain (BP), General Health (GH), Vitality (VT), Social Functioning (SF), Role-Emotional (RE), and Mental Health (MH); Physical Component (PCo), and Mental Component (MCo)

Health. There was no association between the SF-36 score and hypermobility, indicating a minimal impact on the health, physical, and psychosocial aspects of volunteers.

\section{Discussion}

The primary objective was to estimate the frequency of hypermobility among young university students and the possible repercussions on their health condition as evaluated using objective methods. Women were predominantly included in an unselected population, as students of both genders were invited. We found a frequency of $27 \%$ generalized joint hypermobility and an interesting result of $35 \%$ localized hypermobility. Localized signs of hypermobility predominated on the hands and secondarily on the elbows, knees, and spine. The selection of volunteers in medical and physiotherapy schools was aimed at achieving a homogeneous sample of the healthy population with regular physical activity.

The frequency of generalized hypermobility found in our study in young people was similar to that of English adolescents reported by Clinch et al. 2011 [16] using the same threshold of more than 4 points in the Beighton scale found in the cohort up to 14 years old, with proportions of $27.5 \%$ in girls and $10.6 \%$ in boys. Accordingly, $45 \%$ of the girls had finger hypermobility compared with $29 \%$ of boys with finger hypermobility. These authors also did not describe any associations between hypermobility and physical activity, body mass index, or maternal education level.

A recent study among Korean girls and women [44] described the presence of generalized hypermobility in $50 \%$ of respondents, $59 \%$ in girls and $36.5 \%$ in adult women, with the number of signs inversely proportional to age. Significant differences of localized hypermobility in the thumb and 5th finger were found in both groups. The lower frequency of hypermobility according to age occurred symmetrically on both thumbs but it was more pronounced in the fifth finger of the dominant hand, more often on the right hand.

Based on anthropometric data including weight, height, and body mass index, overweight was occasional, and physical activity was relatively regular, with a higher proportion of patients with localized hypermobility, especially in the hands. Population studies are described in the pediatric literature, but data on their frequency, effects, and consequences in the young adult population have been infrequent. Musculoskeletal pain is a sign often related to hypermobility and obesity; sedentary lifestyle may play a relevant role $[45,46]$, as there is a two-fold increased risk in adolescents with hypermobility.

Although the Bodily Pain domain had minimum impact or correlation with hypermobility in the SF-36 investigation, the frequency of musculoskeletal pain was relevant, mainly due to the proportions of low back pain, frequent cramps, arthralgia, and sprains. Long-term studies on sequelae, including the risk of osteoarthritis, are still inconclusive. Conditions such as tendinitis, bursitis, fasciitis, and fibromyalgia correspond to $25 \%$ of referrals to rheumatologists. The association with generalized and localized joint hypermobility, repetitive strain activities, and pain in areas of localized hypermobility [47], has been explored in professional artistic activities such as ballet, gymnastics, and acrobatics $[48,49]$, predisposing to pain and injury due to associated mechanical trauma,.

In a Brazilian study, the prevalence of hypermobility in academic ballet activity was $58 \%$, with a higher frequency among teachers compared with students [49]. It is also interesting to observe the performance of flute players, who have particularly greater range of motion in the hands, and even finger hypermobility, presenting more accurate proprioception through training, which is 
an ideal model to study the interaction between localized flexibility and joint proprioception [50].

Questions about the practice of music or dance activities were not part of our inquiry; we questioned only the number of hours practicing leisure physical activities and sports activities. The options for the Beighton criteria may have some criticism due to variability and divergence in the cutoff scores. The higher scores, such as $\geq 4, \geq 5, \geq 6$, and $\geq 7$ hipermobile joints could also be considered; however, the score $\geq 4$ was the most widely reported in the literature as the most frequent cutoff point $[1,2,11-13,17,20,21,39,49,50]$.

For the diagnosis of generalized joint hypermobility in children and adolescents, at least 5 of the 9 criteria on the Beighton scale are recommended; the difference between the conditions of generalized joint hypermobility and joint hypermobility syndrome is the presence of symptoms. Associated symptoms including predominant musculoskeletal conditions, such as joint pain and instability [26], are more frequently observed in adults and are possibly related to mechanical impact or repeated strain activity.

However, dysfunctional gastrointestinal manifestations $[32,40]$, such as constipation, vesicoureteral reflux [3], or inguinal hernia [31], are more frequently described in pediatric age. Our survey was limited in the approach of other systems involved. Among the systemic manifestations, poor wounds healing, which had a low frequency of responses, was questioned. In the recall survey about pain in the lumbar spine region and arthralgia, these complaints were the most frequent, involving 319 reports in total, but without repercussions on quality of life and health status. Our data are consistent with Ruperto et al. 2004 [25], who used the CHQ-PF 50 questionnaire among healthy schoolchildren with hypermobility and also did not identify repercussions in their physical and psychosocial components.

Musculoskeletal pain can be triggered by physical activity in the absence of adequate physical conditioning, intense physical exercise, an accident, or a traumatic event or may develop without any apparent reason; its association with hypermobility mmay be of mere chance. There are also associations of chronic pain with fatigue, dysautonomia, and negative impacts on quality of life scores due to anxiety and depression [28], which require intervention. However, these associations have been reported in samples of symptomatic hypermobile individuals who seek clinical treatment, comprising approximately $1 \%$ of men and $5 \%$ of women.

More comprehensive population studies including healthy individuals are still needed to estimate the magnitude of the problem and the generalization of our results.

\section{Conclusion}

In conclusion this young population sample with a predominance of women, localized hypermobility was more frequent than generalized hypermobility; however, there was minimum impact on either health or quality of life.

\section{Acknowledgments \\ Darcisio Hortelan Antonio attended the Public Health Graduate Course, Sao Paulo State University (Universidade Estadual Paulista - UNESP), accredited by the Brazilian Federal Agency for the Support and Evaluation of Graduate Education (CAPES). Claudia Saad Magalhães MD, graduate mentor was funded by CNPq Scholarship (301644-2010, 301479/2015). The students Fabricio Lopes Stafussi, Juliana de Freitas, and Susan Nawaly collaborated in the data collection and Prof. José Eduardo Corrente (UNESP) perfomed the statistical analysis.}

\section{Availability of data and materials}

The original data basis that generated the work is filed by the first Author Darcisio Hortelan Antonio.

\section{Authors' contributions}

Both authors contributed equally to the paper development. It was developed as master's thesis under the Public Health Graduate Programme at UNESP.

\section{Authors' information}

No other than the above disclosure and acknowledgement.

\section{Ethics approval and consent to participate}

The project obtained institutional ethics committee approval (CEP-457/2010) and agreement from the undergraduate course councils of the Medical School and Physiotherapy School; the subjects who agreed were included in the study by signing the Terms of Free and Informed Consent. The research was conducted in accordance with the Helsinki Declaration for research on humans beings.

\section{Competing interests}

There is no other competing interest than the academic research.

\section{Publisher's Note}

Springer Nature remains neutral with regard to jurisdictional claims in published maps and institutional affiliations.

Received: 26 March 2018 Accepted: 19 April 2018

Published online: 24 May 2018

\section{References}

1. Kirk JA, Ansell BM, Bywaters EG. The hypermobility syndrome. Musculoskeletal complaints associated with generalized joint hypermobility. Ann Rheum Dis. 1967;26:419-25.

2. Jessee EF, Owen DS Jr, Sagar KB. The benign hypermobile joint syndrome. Arthritis Rheum. 1980;23:1053-6.

3. Klemp P, Stevens JE, Isaacs SA. Hypermobility study in ballet dancers. J Rheumatol. 1984;11:692-6.

4. Scheper MC, Engelbert RH, Rameckers EA, Verbunt J, Remvig L, JuulKristensen B Children with generalised joint hypermobility and musculoskeletal complaints: state of the art on diagnostics, clinical characteristics, and treatment. Biomed Res Int 2013:12105 [http;//dx.doi.org/ https://doi.org/10.1155/2013/121054].

5. Murray KJ. Hypermobility disorders in children and adolescents. Best Pract Res Clin Rheumatol. 2006;20:329-51.

6. Grahame R. Joint hypermobility and genetic collagen disorders: are they related? Arch Dis Child. 1999;80:188-91.

7. Simmonds JV, Keer RJ. Hypermobility and the hypermobility syndrome. Man Ther. 2007;12:298-309.

8. Fikree A, Aziz Q, Grahame R. Joint hypermobility syndrome. Rheum Dis Clin N Am. 2013;39:419-30.

9. Simmonds JV, Keer RJ. Hypermobility and the hypermobility syndrome, part 2: assessment and management of hypermobility syndrome: illustrated via case studies. Man Ther. 2008;13:e1-11.

10. Santos MC, Azevedo ES. Generalized joint hypermobility and black admixture in school children of Bahia, Brazil. Am J Phys Anthropol. 1981;55:43-6. 
11. Larsson LG, Baum J, Mudholkar GS. Hypermobility: features and differential incidence between the sexes. Arthritis Rheum. 1987;30:1426-30.

12. Rikken-Bultman DG, Wellink L, van Dongen PW. Hypermobility in two Dutch school populations. Eur J Obstet Gynecol Reprod Biol. 1997:73:189-92.

13. Jansson A, Saartok T, Werner S, Renstrom P. General joint laxity in 1845 Swedish school children of different ages: age- and gender-specific distributions. Acta Paediatr. 2004;93:1202-6.

14. Lamari NM, Chueire AG, Cordeiro JA. Analysis of joint mobility patterns among preschool children. Sao Paulo Med J. 2005;12:119-23.

15. Hasija RP, Khubchandani RP, Shenoi S. Joint hypermobility in Indian children. Clin Exp Rheumatol. 2008;26:146-50.

16. Clinch J, Deere K, Sayers A, Palmer S, Riddoch C, Tobias JH, Clark EM. Epidemiology of generalized joint laxity (hypermobility) in fourteen-year-old children from the UK: a population-based evaluation. Arthritis Rheum. 2011; 63:2819-27.

17. Abujam B, Aggarwal A. Hypermobility is related with musculoskeletal pain in Indian school-children. Clin Exp Rheumatol. 2014;32:610-3.

18. Remvig $L$, Jensen DV. Ward RC are diagnostic criteria for general joint hypermobility and benign joint hypermobility syndrome based on reproducible and valid tests? A review of the literature. J Rheumatol. 2007; 34:798-803.

19. Ohman A, Westblom C, Henriksson M. Hypermobility among school children aged five to eight years: the hospital del mar criteria gives higher prevalence for hypermobility than the Beighton score. Clin Exp Rheumatol. 2014;32:285-90.

20. Beighton P, Solomon L, Soskolne CL. Articular mobility in an African population. Ann Rheum Dis. 1973;32:413-8.

21. Forleo LH, Hilario MO, Peixoto AL, Naspitz C, Goldenberg J. Articular hypermobility in school children in Sao Paulo, Brazil. J Rheumatol. 1993;20: 916-7.

22. Subramanyam V. Janaki KV joint hypermobility in south Indian children. Indian Pediatr. 1996:33:771-2

23. El-Garf AK, Mahmoud GA. Mahgoub EH hypermobility among Egyptian children: prevalence and features. J Rheumatol. 1998;25:1003-5.

24. Qvindesland A, Jonsson $\mathrm{H}$. Articular hypermobility in Icelandic 12-year-olds. Rheumatology (Oxford). 1999;38:1014-6.

25. Ruperto N, Malattia C, Bartoli M, Trail L, Pistorio A, Martini A, Ravelli A. Functional ability and physical and psychosocial well-being of hypermobile schoolchildren. Clin Exp Rheumatol. 2004;22:495-8.

26. Adib N, Davies K, Grahame R, Woo P, Murray KJ. Joint hypermobility syndrome in childhood. A not so benign multisystem disorder? Rheumatology (Oxford). 2005;44:744-50.

27. Pacey V, Tofts L, Wesley A, Collins F, Singh-Grewal D. Joint hypermobility syndrome: a review for clinicians. J Paediatr Child Health. 2015:51:373-80.

28. Palmer S, Bailey S, Barker L, Barney L, Elliott A. The effectiveness of therapeutic exercise for joint hypermobility syndrome: a systematic review. Physiotherapy. 2014;100:220-7.

29. Mishra MB, Ryan P, Atkinson P, Taylor H, Bell J, Calver D, et al. Extra-articular features of benign joint hypermobility syndrome. Brit J Rheumatol. 1996;35: 861-6.

30. Beiraghdar F, Rostami Z, Panahi Y, Einollahi B, Teimoori M. Vesicourethera reflux in pediatrics with hypermobility syndrome. Nephrourol Mon. 2013;5: 924-7.

31. Nazem M, Mottaghi $P$, Hoseini A. Khodadadi HA benign joint hypermobility syndrome among children with inguinal hernia. J Res Med Sci. 2013;18:904-5.

32. Kovacic K, Chelimsky TC, Sood MR, Simpson P, Nugent M, Chelimsky G. Joint hypermobility: a common association with complex functional gastrointestinal disorders. J Pediatr. 2014;165:973-8.

33. Roberto AM, Terreri MT, Szejnfeld V, Hilario MO. Bone mineral density in children. Association with musculoskeletal pain and/or joint hypermobility. J Pediatr. 2002;78:523-8

34. Albayrak I, Yilmaz H, Akkurt HE, Salli A, Karaca G. Is pain the only symptom in patients with benign joint hypermobility syndrome? Clin Rheumatol. 2015;34:1613-9

35. Engelbert RH, Bank RA, Sakkers RJ, Helders PJ, Beemer FA, Uiterwaal CS. Pediatric generalized joint hypermobility with and without musculoskeleta complaints: a localized or systemic disorder? Pediatrics. 2003;111:e248-54.

36. Cameron KL, Duffey ML, De Berardino TM, Stoneman PD, Jones CJ, Owens $\mathrm{BD}$. Association of generalized joint hypermobility with a history of glenohumeral joint instability. J Athlet Train. 2010;45:253-8.
37. Kavuncu V, Sahin S, Kamanli A, Karan A, Aksoy C. The role of systemic hypermobility and condylar hypermobility in temporomandibular joint dysfunction syndrome. Rheumatol Int. 2006;26:257-60.

38. Azma K, Mottaghi $\mathrm{P}$, Hosseini A, Abadi HH. Nouraei MH benign joint hypermobility syndrome in soldiers; what is the effect of military training courses on associated joint instabilities? J Res Med Sci. 2014;19:639-43.

39. Marcolin ALV, Cardin SP, Magalhaes CS. Muscle strength assessment among children and adolescents with growing pains and joint hypermobility. Rev Bras Fisiot. 2009;13:110-5.

40. Farmer AD, Fikree A, Aziz Q. Addressing the confounding role of joint hypermobility syndrome and gastrointestinal involvement in postural orthostatic tachycardia syndrome. Clin Autonom Res. 2014;24:157-8.

41. Moraes DA, Baptista CA, Crippa JA, Louzada-Junior P. Translation into Brazilian Portuguese and validation of the five-part questionnaire for identifying hypermobility. Rev Bras Reumatol. 2011:51:53-69.

42. da Mota Falcao D, Ciconelli RM. Ferraz MB translation and cultural adaptation of quality of life questionnaires: an evaluation of methodology. J Rheumatol. 2003;30:379-85.

43. Remvig L, Jensen DV. Ward RC epidemiology of general joint hypermobility and basis for the proposed criteria for benign joint hypermobility syndrome: review of the literature. J Rheumatol. 2007;34:804-9.

44. Kwon JW, Lee WJ, Park SB, Kim MJ, Jang SH, Choi CK. Generalized joint hypermobility in healthy female koreans: prevalence and age-related differences. Ann Rehab Med. 2013;37:832-8.

45. Tobias JH, Deere K, Palmer S, Clark EM, Clinch J. Joint hypermobility is a risk factor for musculoskeletal pain during adolescence: findings of a prospective cohort study. Arthritis Rheum. 2013;65:1107-15.

46. Sperotto F, Balzarin M, Parolin M, Monteforte N, Vittadello F, Zulian F. Joint hypermobility, growing pain and obesity are mutually exclusive as causes of musculoskeletal pain in schoolchildren. Clin Exp Rheumatol. 2014;32:131-6.

47. Hudson N, Fitzcharles MA, Cohen M, Starr MR, Esdaile JM. The association of soft-tissue rheumatism and hypermobility. Brit J Rheumatol. 1998;37:382-6.

48. McCormack M, Briggs J, Hakim A, Grahame R. Joint laxity and the benign joint hypermobility syndrome in student and professional ballet dancers. J Rheumatol. 2004:31:173-8.

49. Sanches SB, Oliveira GM, Osorio FL, Crippa JA, Martin-Santos R. Hypermobility and joint hypermobility syndrome in Brazilian students and teachers of ballet dance. Rheumatol Int. 2015;35:741-7.

50. Artigues-Cano I, Bird HA. Hypermobility and proprioception in the finger joints of flautists. J Clin Rheumatol. 2014;20:203-8.

\section{Ready to submit your research? Choose BMC and benefit from:}

- fast, convenient online submission

- thorough peer review by experienced researchers in your field

- rapid publication on acceptance

- support for research data, including large and complex data types

- gold Open Access which fosters wider collaboration and increased citations

- maximum visibility for your research: over $100 \mathrm{M}$ website views per year

At BMC, research is always in progress.

Learn more biomedcentral.com/submissions 